\title{
Dentin bonding performance of experimental one-step adhesives after incorporation of $\mathrm{POOH}-\mathrm{SiO}_{2}$ nanoparticles
}

\author{
Carine Tais Welter Meereis ${ }^{1 *}$, Carlos Enrique Cuevas Suárez ${ }^{1,2}$, Suzanne Mendes de Almeida1, \\ Carianne Mendes de Almeida ${ }^{1}$, Evandro Piva ${ }^{1 *}$, Fabrício Mezzomo Collares ${ }^{3}$ and Fabrício Aulo Ogliari ${ }^{1,4}$
}

*Correspondence: carinemeereis@gmail.com; evpiva@gmail.com

${ }^{1}$ Biomaterials Development and Control Center, School of Dentistry, Federal University of Pelotas, Gonçalves Chaves 457, Pelotas 96015-560, Brazil Full list of author information is available at the end of the article

\begin{abstract}
This study investigated the effect of adding different concentrations of phosphategrafted-silica nanoparticles $\left(\mathrm{SiO}_{2}-\mathrm{POOH}\right)$ on dentin bond strength of experimental one-step self-etching adhesives (1-SEAs). Phosphate functional group was grafted onto silica nanoparticles through the free radical polymerization of an acid phosphate monomer [methacryloyloxyethyl dihydrogen phosphate/bis (methacryloyloxyethyl) hydrogen phosphate-HEMA-P] in an alcoholic medium. The resulting $\mathrm{SiO}_{2}-\mathrm{POOH}$ was characterized by FTIR spectroscopy. 1-SEA with two different acidic phosphate monomer concentrations (HEMA-P at 0 and $40 \% \mathrm{wt}$ ) were prepared and $\mathrm{SiO}_{2}-\mathrm{POOH}$ was added in 0 (control), $0.1,0.2,0.5,1,2,4,6$ and $8 \mathrm{wt} \%$. The formulated 1-SEAs were evaluated for shear bond strength to dentin. Statistical comparisons were conducted at $5 \%$ significance level. The grafting reaction of $\mathrm{SiO}_{2}-\mathrm{POOH}$ was confirmed by FTIR. Compared with the unfilled 1-SEA, the addition of $0.1 \mathrm{wt} \%$ of $\mathrm{SiO}_{2}-\mathrm{POOH}$ nanoparticles resulted in a significant dentin bond strength increase for $\mathrm{HEMA}-\mathrm{P}_{40 \%}$ concentration ( $p \leq 0.001$ ) while the addition of higher concentration of $\mathrm{SiO}_{2}-\mathrm{POOH}(0.2,0.5,1,2,4$, 6 and $8 \mathrm{wt} \%$ ) reduced significantly the bond strength. The 1-SEA formulated without an acidic monomer (HEMA- $\mathrm{P}_{0 \%}$ ) did not exhibit bonding to the dentin, irrespective of $\mathrm{SiO}_{2}-\mathrm{POOH}$ concentration added. $\mathrm{SiO}_{2}-\mathrm{POOH}$ nanoparticles were obtained through graft polymerization of acidic phosphate monomer with silanized $\mathrm{SiO}_{2}$ nanoparticles. The addition of the $0.1 \mathrm{wt} \%$ of $\mathrm{SiO}_{2}-\mathrm{POOH}$ nanoparticles associated with acidic monomer to 1-SEA improves the bonding effectiveness.
\end{abstract}

Keywords: Dental adhesives, Dentin bonding agents, Filler, Graft polymerization, Acidic monomers, Bond strength

\section{Background}

The bonding effectiveness to dental tissue is related to a material's ability to promote demineralization of the substrate, resin infiltration, and form a hydrolysis-resistant hybrid layer (a polymer setting and collagen network) [1]. In self-etch adhesives, the acidic methacrylate monomer promotes physical-chemical interactions between the adhesive and dental tissue by micro-mechanical interlocking and additional chemical interaction [2]. The phosphate acidic functional groups of it monomers could interact with calcium ions of hydroxyapatite and improve the bond durability $[2,3]$. Thus 
a reliable bonding depends on the mechanical and chemical behavior of the polymer formed.

However, this acidic monomer affect the polymerization reaction $[4,5]$ and become hydrolytically unstable in one-bottle materials, [6-8] thus increasing the water sorption and decreasing the mechanical properties of the polymer [1]. Such increase in water affinity allows water movement through the adhesive layer $[9,10]$, and as consequence small droplets can be found at the transition layer between adhesive and lining composite [11]. This phenomenon promotes a decrease in bond strength and seems to contribute to the hydrolysis of the adhesive layer and consequently degradation over time [12]. This hybrid layer is considered the weakest spot of an adhesive restoration and, thus, is more likely to fail $[1,10,13]$. Therefore, improving the material's properties and enhancing the physical-chemical interaction of tooth-adhesive will lead to a more durable restorative treatment $[1,2]$.

Several commercial adhesives systems present filler particles in their constitution [14, 15]. It has previously demonstrated that the addition of nanoparticles (NPs) to adhesives increases the mechanical properties and bond strength [16-19]; however, specific nanoparticle dispersion state is necessary to optimize these properties. Grafting is an effective method to control the NPs dispersion in a polymer matrix, as well as to give specific surface characteristics [20]. Therefore, the aim of this study was to evaluate the effect of adding different concentrations of phosphate acidic functional groups grafted on silica nanoparticles surface $\left(\mathrm{SiO}_{2}-\mathrm{POOH}\right)$ on dentin bond strength of experimental one-step self-etching adhesives (1-SEAs). The hypothesis tested was that the incorporation of $\mathrm{SiO}_{2}-\mathrm{POOH}$ improved the bonding strength of the 1-SEA.

\section{Methods}

Reagents

The silica nanoparticles $\left(\mathrm{SiO}_{2}\right.$-Aerosil ${ }^{\circledR} 380 / 7 \mathrm{~nm}$ average size, Degussa, Germany) were silanized by gamma-methacryloxypropyltrimethoxysilane ( $\gamma$-MPTS-Aldrich Chemical Co., USA) and grafted by acidic phosphate monomer (methacryloyloxyethyl dihydrogen phosphate/bis (methacryloyloxyethyl) hydrogen phosphate-HEMA-P) that was synthesized as previously described [21]. Acetic acid, benzoyl peroxide (BPO), acetone, and ethanol were purchased from Vetec, Brazil and used as received. Distilled water was used throughout all of the experiments. The experimental 1-SEAs were formulated by monomers 2,2-bis[4-(2-hydroxy-3-methacryloyloxy propyl)phenyl]-propane (BisGMA), (di)methacrylate monomers urethane dimethacrylate (UDMA), 2-hydroxyethyl methacrylate (HEMA) and trietilenglicol dimethacrylate (TEGDMA) which were supplied by Esstech Inc., USA, and used as received. The photosensitizer, camphorquinone (CQ-Esstech), as well as the co-initiator ethyl 4-(dimethylamino) benzoate (EDAB) and diphenyliodonium hexafluorphosphate (DPIHFP), were purchased from Aldrich Chemical Co, USA, were used to render the materials photocurable.

\section{Graft polymerization of phosphate onto the $\mathrm{SiO}_{2}$ nanoparticle}

In a 500-mL round-bottom vessel connected to a reflux condenser, $\gamma$-MPTS and acetic acid (10 and $15 \%$ wt of the nanoparticles wt, respectively) were dissolved in $15 \mathrm{~mL}$ of distilled water and $150 \mathrm{~mL}$ of ethanol. $5 \mathrm{~g}$ of $\mathrm{SiO}_{2}$ was added to this mixture. The 
temperature was held at $80^{\circ} \mathrm{C}$ for $24 \mathrm{~h}$ while being vigorously stirred. $\mathrm{SiO}_{2}$ silanization was confirmed through appearing the $\mathrm{C}=\mathrm{C}$ signal at $1636 \mathrm{~cm}^{-1}$ in the Fourier transform mid-infrared (FTIR) spectrum. The acidic phosphate monomer HEMA-P and BPO as radical initiator ( 15 and $1 \%$ wt of the nanoparticles $w t$, respectively) were then added to the reaction medium. The temperature was maintained at $80{ }^{\circ} \mathrm{C}$ while stirring. The polymerization reaction was left to take place for $24 \mathrm{~h}$. The product was washed with acetone three times to remove the unreacted monomers and dried at room temperature for $24 \mathrm{~h}$, resulting in silica powder with phosphate-functional groups at their surface $\left(\mathrm{SiO}_{2}-\mathrm{POOH}\right)$. Schematic representation of graft polymerization of phosphate onto the silanized $\mathrm{SiO}_{2}$ nanoparticle is summarized in Fig. 1.

\section{Particles' characterization}

The $\mathrm{SiO}_{2}$ and $\mathrm{SiO}_{2}-\mathrm{POOH}$ were analyzed by Fourier transform mid-infrared (FTIR) spectroscopy (Prestige-21; Shimadzu, Japan) at a resolution of $4 \mathrm{~cm}^{-1}$ and 24 scans in the range of $700-2500 \mathrm{~cm}^{-1}$. The $\mathrm{SiO}_{2}$ was used as background before the $\mathrm{SiO}_{2}-\mathrm{POOH}$ analysis to avoid overlapping the peaks between 500 and $1500 \mathrm{~cm}^{-1}$.

\section{Experimental one-step self-etch adhesive (1-SEA) formulations}

A model 1-SEA was prepared through mixing of Bis-GMA (42.5\% wt), HEMA (38\% wt), TEGDMA (8.5\% wt), UDMA (8.5\% wt); and a ternary initiation system CQ $(0.5 \% \mathrm{wt})$, EDAB (1\% wt) and DPIHFP (1\% wt). 1-SEA with two different acidic phosphate monomer concentrations (HEMA-P at 0 and $40 \% \mathrm{wt}$ ) were prepared. $\mathrm{SiO}_{2}-\mathrm{POOH}$ was added to the 1-SEA in 0 (control), 0.1, 0.2, 0.5, 1, 2, 4, 6 and $8 \mathrm{wt} \%$. To perform monomer photoactivation, a light-emitting diode unit (LED-Radii; SDI, Australia) was used. An

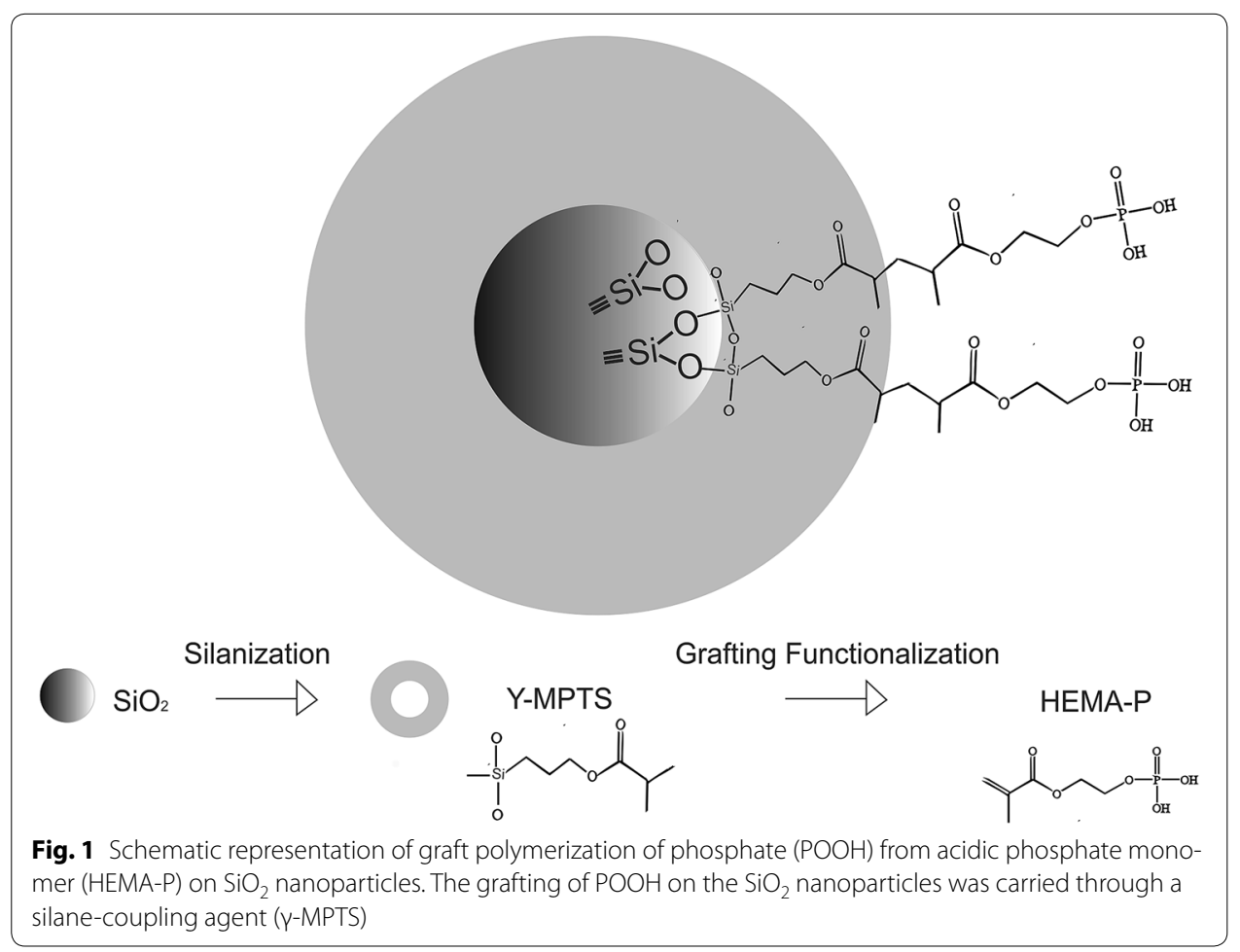


irradiation value of $1400 \mathrm{~mW} / \mathrm{cm}^{-2}$ was confirmed with a power meter (Ophir Optronics, USA).

\section{Shear bond strength to dentin}

Sixty bovine incisors were embedded in epoxy resin and their buccal faces were wetground to expose the dentin $(n=10)$. The dentin surfaces were wet-polished with 600grit $\mathrm{SiC}$ abrasive papers for $60 \mathrm{~s}$. Dentin moisture was controlled with absorbent paper until no surface water was observed. The 1-SEAs were vigorously applied to the prepared dentin surfaces for $20 \mathrm{~s}$ by using a microbrush; elastomer molds (thickness $0.5 \mathrm{~mm}$ ) with a cylindrical orifice (diameter $1.5 \mathrm{~mm}$ ) were placed onto the adhesive layer and lightactivated for $30 \mathrm{~s}$. The orifices were filled with the resin composite (Filtek Z250, $3 \mathrm{M}$ ESPE, USA) to produce cylindrical specimens with bonded area of $1.77 \mathrm{~mm}^{2}$; the molds were covered with a polyester strip and a glass slide and the resin composite was photoactivated for $40 \mathrm{~s}$. After storage in distilled water at $37^{\circ} \mathrm{C}$ for $24 \mathrm{~h}$, a thin steel wire (diameter $0.2 \mathrm{~mm}$ ) was looped around the cylinder and aligned with the bonding interface. The shear test was conducted at a crosshead speed of $0.5 \mathrm{~mm} \mathrm{~min}^{-1}$ until failure in a universal testing machine (EMIC DL 500, Brazil). Shear bond strength (SBS) values were calculated in MPa.

\section{Statistical analysis}

The SBS data were submitted to Kruskal-Wallis one-way Analysis of Variance and the Student-Newman-Keuls test $(\mathrm{p}<0.05)$.

\section{Results}

Figure 2 shows the FTIR spectra of the $\mathrm{SiO}_{2}-\mathrm{POOH}$ illustrating the characteristic peaks of the $\mathrm{POOH}$ functional groups which confirms the grafting process. $\mathrm{SiO}_{2}-\mathrm{POOH}$ spectrum shows the presence of peaks at about 801 and $1053 \mathrm{~cm}^{-1}$, which are assigned to the $\mathrm{POOH}$ functional group [21]. Also, spectrum shows peaks at $1730 \mathrm{~cm}^{-1}$, which

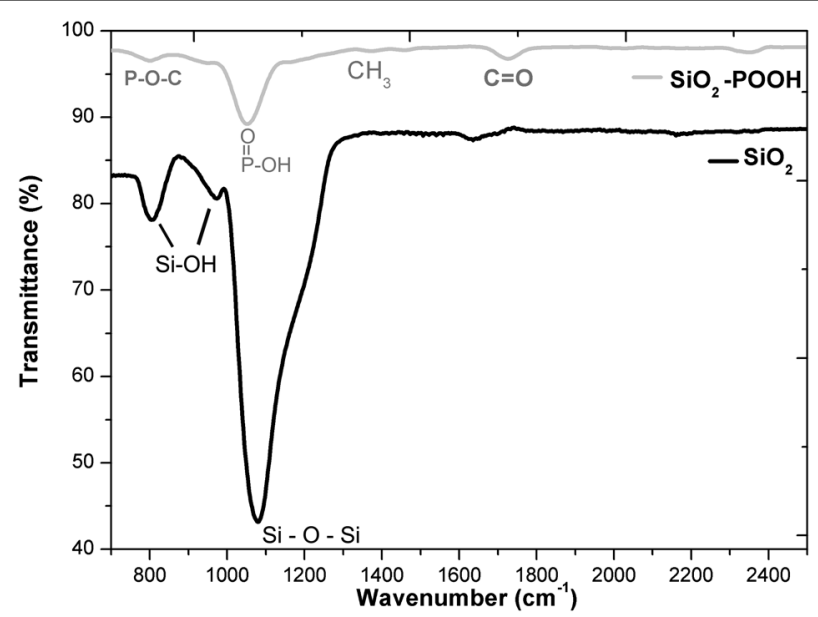

Fig. 2 FTIR spectra of $\mathrm{SiO}_{2}$ and $\mathrm{SiO}_{2}-\mathrm{POOH}$. ${ }^{*}$ The $\mathrm{SiO}_{2}$ sample was used as background prior the $\mathrm{SiO}_{2}-\mathrm{POOH}$ analysis to avoid peaks' overlapping between 500 and $1500 \mathrm{~cm}^{-1}$ 
corresponds to the methacrylate $\mathrm{C}=\mathrm{O}$ stretching vibrations and peaks at 1374 and $1379 \mathrm{~cm}^{-1}$, which are assigned the $\mathrm{CH}_{3}$ bending deformation of the polymer grafted backbone.

The effect of the $\mathrm{SiO}_{2}-\mathrm{POOH}$ nanoparticles concentration on the dentin bond strength of 1-SEA is shown in Table 1. Compared with the unfilled 1-SEA, the addition of $0.1 \mathrm{wt} \%$ of $\mathrm{SiO}_{2}-\mathrm{POOH}$ nanoparticles resulted in a significant dentin bond strength increase for HEMA- $\mathrm{P}_{40} \%$ concentration $(\mathrm{p} \leq 0.001)$. $\mathrm{SiO}_{2}-\mathrm{POOH}$-containing adhesives in higher concentration $(0.2,0.5,1,2,4,6$ and $8 \mathrm{wt} \%)$ showed a significantly lower bond strength as compared with the HEMA- $\mathrm{P}_{40 \%} / \mathrm{SiO}_{2}-\mathrm{POOH}_{0.1 \%}$ and unfilled 1-SEA. The 1-SEA formulated without an acidic monomer (HEMA- $\mathrm{P}_{0 \%}$ ) did not exhibit bonding to the dentin, irrespective of $\mathrm{SiO}_{2}-\mathrm{POOH}$ concentration added, and hence it was not represented in table. Special interpretation of the SBS-values was performed, in case of a pre-testing failure, shear bond strength value of zero MPa was assigned to specimen, and this data was included into the statistical analysis.

\section{Discussion}

The grafting of $\mathrm{POOH}$ on the $\mathrm{SiO}_{2}$ nanoparticles was carried through a silane-coupling agent. The $\mathrm{SiO}_{2}$ was first functionalized with a silane-coupling agent ( $\gamma$-MPTS) where the hydrolyzed alkoxysilane groups $(\mathrm{Si}-\mathrm{OH})$ from $\gamma$-MPTS reacts with the hydroxyl groups $(\mathrm{OH})$ from $\mathrm{SiO}_{2}$ to form covalent siloxane bonds ( $\mathrm{Si}-\mathrm{O}-\mathrm{Si}-$ ). Remaining methacrylate end functional groups provides active sites for graft copolymerization [22]. The polymerization of the acidic phosphate monomer (HEMA-P) in the presence of silanized $\mathrm{SiO}_{2}$ particles, and a free radical initiator, $\mathrm{PB}$, leads to graft polymerization involving the acrylate groups of $\gamma$-MPTS and HEMA-P.

The covalent linkage between acrylates groups of $\gamma$-MPTS and HEMA-P occurs by breaking of the double bond $\mathrm{C}=\mathrm{C}$ during the free radical polymerization. The percentage of HEMA-P used (15\% wt) correspond a 2:1 molar ratio of $\gamma$-MPTS linked to $\mathrm{SiO}_{2}$ nanoparticles, which ensures complete graft polymerization between both monomers. The absence of the peak at $1636 \mathrm{~cm}^{-1}$ due to stretching vibration of the $\mathrm{C}=\mathrm{C}$ [23] is an evidence of this polymerization process in $\mathrm{SiO}_{2}-\mathrm{POOH}$. Other characteristic peaks appears at 801 and $1053 \mathrm{~cm}^{-1}$, which correspond to aliphatic binding of $\mathrm{P}-\mathrm{O}-\mathrm{C}$ and

Table 1 Median (95\% of confidence interval) for shear bond strength varying $\mathrm{SiO}_{2}-\mathrm{POOH}$ nanoparticles concentration (wt\%) of 1-SEA with HEMA-P $\mathbf{4 0}_{40}$

\begin{tabular}{ll}
\hline HEMA-P $\mathbf{4 0}_{\mathbf{4 0}} / \mathbf{S i O}_{\mathbf{2}}-\mathbf{P O O H}$ concentration, $\mathbf{w t} \%(\%)$ & Dentin bond strength, $\mathbf{M P a}$ \\
\hline 0 & $6.01(1.54)^{\mathrm{b}}$ \\
0.1 & $8.63(1.45)^{\mathrm{a}}$ \\
0.2 & $5.56(2.13)^{\mathrm{c}}$ \\
0.5 & $2.37(2.55)^{\mathrm{d}}$ \\
1 & $2.53(0.90)^{\mathrm{e}}$ \\
2 & $5.56(1.80)^{\mathrm{c}}$ \\
4 & $1.07(1.49)^{\mathrm{e}}$ \\
6 & $3.54(2.19)^{\mathrm{d}}$ \\
8 & $4.19(1.88)^{\mathrm{d}}$ \\
\hline
\end{tabular}

Values followed by distinct superscript letters indicate significant differences for 1-SEAs tested $(p<0.05)$

Note: It was not possible to test any specimens for HEMA-P $\mathrm{P}_{0 \%}$ as all pre-testing failure 
$\mathrm{P}-\mathrm{OH}$ functional groups of HEMA-P structure [21]. Representative peaks at 1730, 1374 and $1379 \mathrm{~cm}^{-1}$ which corresponds to free carbonyl stretching vibration $(\mathrm{C}=\mathrm{O})$ and to $\mathrm{CH}_{3}$ bending deformation can confirm the presence of a polymer backbone grafted to the NPs. Also, as $\mathrm{SiO}_{2}$ sample was used as background prior the $\mathrm{SiO}_{2}-\mathrm{POOH}$ analysis, any of $\mathrm{Si}-\mathrm{O}-\mathrm{Si}$ at $1098 \mathrm{~cm}^{-1}$ and $\mathrm{Si}-\mathrm{OH}$ at $793 \mathrm{~cm}^{-1}$ linkages could not appear into the $\mathrm{SiO}_{2}-\mathrm{POOH}$ spectrum and therefore, it is expected that only linkages corresponding to the $-\mathrm{POOH}$ backbone grafted to the $\mathrm{SiO}_{2}$ surface could be observed [24].

The addition of $0.1 \mathrm{wt} \%$ of $\mathrm{SiO}_{2}-\mathrm{POOH}$ nanoparticles to 1-SEA improved the bonding strength to the dentin, except for 1-SEA formulated without an acidic monomer (HEMA- $\mathrm{P}_{0 \%}$ ) did not exhibit bonding to the dentin, irrespective of $\mathrm{SiO}_{2}-\mathrm{POOH}$ concentration added (data no showed). Therefore, the tested hypothesis should be partially accepted. Self-etch adhesives require acidic functional monomers, such as HEMA-P, to simultaneously condition and prime the dental substrate [2]. In this study, experimental groups without HEMA-P did not exhibit any bonding to dentin because there was not any acidic functional monomer in these 1-SEA's which could promote demineralization and infiltration of the adhesive system. Also, it was possible to confirm that phosphate functional groups grafted on $\mathrm{SiO}_{2}$ nanoparticles does not act as a self-etching agent.

The addition of $0.1 \mathrm{wt} \%$ of $\mathrm{SiO}_{2}-\mathrm{POOH}$ nanoparticles in 1-SEA with HEMA-P, in contrast, resulted in an increased adhesion to dentin. The HEMA- $\mathrm{P}_{40 \%} / \mathrm{SiO}_{2}-\mathrm{POOH}_{0.1 \%}$ showed significantly higher bond strengths $(\approx 50 \%)$ than the correspondent unfilled 1-SEA HEMA- $\mathrm{P}_{40 \%}$. Previous studies have already been proven that the addition of an optimum amount of filler into adhesives increases the mechanical properties and bond strength $[18,19,25]$. The increase in these properties is due an increment of the elastic modulus of the adhesive layer between dentin and restoration. This adhesive layer acts as an elastic buffer which offers the resin-dentin interface a sufficient strain capacity to resist higher debonding forces [26]. Also, it could be theorized that phosphate functional groups attached to solid $\mathrm{SiO}_{2}$ particles could probably promoted an additional chemical interaction with $\mathrm{Ca}^{2+}$ ions of the hydroxyapatite from the dentin [2]. In addition, since it's well known the high hydrophilicity of phosphate acid groups [27], improved dentin bond strength could be achieved due an increase in dentin wettability by 1-SEAs.

The present results indicate that the maximum increases of shear bond strength occurred only when $0.1 \mathrm{wt} \%$ of $\mathrm{SiO}_{2}-\mathrm{POOH}$ was added in 1-SEA with HEMA-P, the increase of filler above this concentration lead to a decrease of dentin bond strength. Correlation for the decreasing of the bond strength to the increasing of $\mathrm{SiO}_{2}-\mathrm{POOH}$ nanoparticles concentration, however, was not found. Surprisingly some groups e.g. $8 \mathrm{wt} \%$ of $\mathrm{SiO}_{2}-\mathrm{POOH}$ presented higher results than 1 and $4 \mathrm{wt} \%$ of $\mathrm{SiO}_{2}-\mathrm{POOH}$. Two possible phenomena could explain this behavior, first the agglomeration of the nanoparticles and subsequently accumulation of these filler agglomerates on the top of the conditioned dentin prevent the resin infiltration into the dentinal tubules; and on the other hand, higher filler concentrations increase significantly the viscosity of the adhesive systems, which also reduces the penetration of the 1-SEA [15]. Both mechanisms seem to prevent optimal adaptation of the adhesive into the dentin surface, and consequently bond strength and marginal integrity is compromised [15]. Also, it was shown that fillers into adhesive systems yield thicker adhesive layers, which can affect its capacity to relief contraction stresses produced by the restorative composite [26]. This is in agreement 
with other studies that also showed a high level of bond strength to dentin with the addition of a small amount of filler to the adhesive $[16,18,19,28]$. These effects, however, should be addressed in future studies. The improvement bonding efficacy of 1-SEA's modified with $\mathrm{SiO}_{2}-\mathrm{POOH}$ nanoparticles, under clinical conditions, could improve the clinical service of restorations, as well as render a clinical procedure simpler, more userfriendly, and less technique-sensitive.

\section{Conclusion}

$\mathrm{SiO}_{2}-\mathrm{POOH}$ nanoparticles were obtained through graft polymerization of acidic phosphate monomer with silanized $\mathrm{SiO}_{2}$ nanoparticles. The addition of the $0.1 \mathrm{wt} \%$ of $\mathrm{SiO}_{2}-\mathrm{POOH}$ nanoparticles associated with acidic monomer to experimental one-step self-etching adhesives improves the bonding effectiveness.

\section{Authors' contributions}

CTWM, CECS, SMA and CMA confectioned the specimens, performed the mechanical test, conducted the statistical analysis and write the manuscript. FMC, EP and FAO delineated the experiment and help in the manuscript written. All authors read and approved the manuscript.

\section{Author details \\ ${ }^{1}$ Biomaterials Development and Control Center, School of Dentistry, Federal University of Pelotas, Gonçalves Chaves 457, Pelotas 96015-560, Brazil. ${ }^{2}$ Dental Materials Laboratory, Academic Area of Dentistry, Autonomous University of the State of Hidalgo, Circuito ex-Hacienda la Concepción Km. 1.5, 42160 Pachuca, Mexico. ${ }^{3}$ Dental Materials Laboratory, School of Dentistry, Federal University of Rio Grande do Sul, Ramiro Barcelos 2492, Porto Alegre 90035-004, Brazil. ${ }^{4}$ Department of Organic Chemistry, School of Materials Engineering, Federal University of Pelotas, Félix da Cunha 448, Pelotas 96010-000, Brazil.}

\section{Acknowledgements}

This work was supported by the Conselho Nacional de Pesquisa (CNPq) and Financiadora de estudos e projetos (FINEP) Grant 01.10.0709.00, Brazil. Authors are grateful to CAPES/Brazil for the scholarship and Angelus Ind. Ltda for $\mathrm{SiO}_{2}$ nanoparticles donation.

Competing interests

The authors declare that they have no competing interests.

Received: 25 October 2016 Accepted: 25 November 2016

Published online: 01 December 2016

\section{References}

1. Breschi L, Mazzoni A, Ruggeri A, Cadenaro M, Di Lenarda R, Dorigo EDS. Dental adhesion review: aging and stability of the bonded interface. Dent Mater. 2008;24:90-101.

2. Van Meerbeek B, Yoshihara K, Yoshida Y, Mine A, De Munck J, Van Landuyt K. State of the art of self-etch adhesives. Dent Mater. 2011;27:17-28.

3. Fu B, Sun X, Qian W, Shen Y, Chen R, Hannig M. Evidence of chemical bonding to hydroxyapatite by phosphoric acid esters. Biomaterials. 2005;26:5104-10.

4. Adusei G, Deb S, Nicholson JW, Mou L, Singh G. Polymerization behavior of an organophosphorus monomer for use in dental restorative materials. J Appl Polym Sci. 2003;88:565-9.

5. Meereis CT, Leal FB, Ogliari FA. Stability of initiation systems in acidic photopolymerizable dental material. Dent Mater. 2016;32:889-98.

6. Sadr A, Ghasemi A, Shimada Y, Tagami J. Effects of storage time and temperature on the properties of two selfetching systems. J Dent. 2007;35:218-25.

7. Fujita K, Nishiyama N. 13C NMR analysis of the etching efficacy of acidic monomers in self-etching primers. J Dent. 2006:34:123-33.

8. Salz U, Zimmermann J, Zeuner F, Moszner N. Hydrolytic stability of self-etching adhesive systems. J Adhes Dent. 2005:7:107-16.

9. Tay FR, Pashley DH, Suh BI, Carvalho RM, Itthagarun A. Single-step adhesives are permeable membranes. J Dent. 2002:30:371-82.

10. Tay FR, Pashley DH, Hiraishi N, Imazato S, Rueggeberg FA, Salz U, et al. Tubular occlusion prevents water-treeing and through-and-through fluid movement in a single-bottle, one-step self-etch adhesive model. J Dent Res. 2005:84:891-6.

11. Van Landuyt KL, Snauwaert J, Peumans M, De Munck J, Lambrechts P, Van Meerbeek B. The role of HEMA in one-step self-etch adhesives. Dent Mater. 2008;24:1412-9. 
12. Hashimoto M, Ohno H, Sano H, Kaga M, Oguchi H. In vitro degradation of resin-dentin bonds analyzed by microtensile bond test, scanning and transmission electron microscopy. Biomaterials. 2003;24:3795-803.

13. Belli R, Sartori N, Peruchi LD, Guimaraes JC, Araujo E, Monteiro S Jr, et al. Slow progression of dentin bond degradation during one-year water storage under simulated pulpal pressure. J Dent. 2010;38:802-10.

14. Di Hipolito V, Reis AF, Mitra SB, de Goes MF. Interaction morphology and bond strength of nanofilled simplified-step adhesives to acid etched dentin. Eur J Dent. 2012;6:349-60.

15. Van Landuyt KL, Snauwaert J, De Munck J, Peumans M, Yoshida Y, Poitevin A, et al. Systematic review of the chemical composition of contemporary dental adhesives. Biomaterials. 2007;28:3757-85.

16. Atai M, Solhi L, Nodehi A, Mirabedini SM, Kasraei S, Akbari K, et al. PMMA-grafted nanoclay as novel filler for dental adhesives. Dent Mater. 2009;25:339-47.

17. Kim S, Kim E, Kim S, Kim W. Surface modification of silica nanoparticles by UV-induced graft polymerization of methyl methacrylate. J Colloid Interface Sci. 2005;292:93-8.

18. Solhi L, Atai M, Nodehi A, Imani M. A novel dentin bonding system containing poly (methacrylic acid) grafted nanoclay: synthesis, characterization and properties. Dent Mater. 2012;28:1041-50.

19. Solhi L, Atai M, Nodehi A, Imani M, Ghaemi A, Khosravi K. Poly (acrylic acid) grafted montmorillonite as novel fillers for dental adhesives: synthesis, characterization and properties of the adhesive. Dent Mater. 2012;28:369-77.

20. Kumar SK, Jouault N, Benicewicz B, Neely T. Nanocomposites with polymer grafted nanoparticles. Macromolecules. 2013:46:3199-214

21. Lima Gda S, Ogliari FA, da Silva EO, Ely C, Demarco FF, Carreno NL, et al. Influence of water concentration in an experimental self-etching primer on the bond strength to dentin. J Adhes Dent. 2008;10:167-72.

22. Antonucci JM, Dickens SH, Fowler BO, Xu HHK, McDonough WG. Chemistry of silanes: interfaces in dental polymers and composites. J Res Natl Inst Stand Technol. 2005:110:541-58.

23. Leitune VC, Collares FM, Takimi A, de Lima GB, Petzhold CL, Bergmann CP, et al. Niobium pentoxide as a novel filler for dental adhesive resin. J Dent. 2013;41:106-13.

24. Mahmood N, Khan MS, Khan AU, Stockelhuber KW, Heinrich G. Purification, surface modification of coal ash silica and its potential application in rubber composites. J Appl Polym Sci. 2010;117:1493-501.

25. Menezes $L R$, Silva EO. The use of montmorillonite clays as reinforcing fillers for dental adhesives. Mater Res. 2016;19(1):236-42.

26. Van Meerbeek B, Willems G, Celis J-P, Roos J, Braem M, Lambrechts P, et al. Assessment by nano-indentation of the hardness and elasticity of the resin-dentin bonding area. J Dent Res. 1993;72:1434-42.

27. Cramer N, Stansbury J, Bowman C. Recent advances and developments in composite dental restorative materials. J Dent Res. 2011;90:402-16.

28. Kim JS, Cho BH, Lee IB, Um CM, Lim BS, Oh MH, et al. Effect of the hydrophilic nanofiller loading on the mechanical properties and the microtensile bond strength of an ethanol-based one-bottle dentin adhesive. J Biomed Mater Res B Appl Biomater. 2005;72:284-91.

\section{Submit your manuscript to a SpringerOpen ${ }^{\circ}$ journal and benefit from:}

- Convenient online submission

- Rigorous peer review

- Immediate publication on acceptance

- Open access: articles freely available online

- High visibility within the field

- Retaining the copyright to your article

Submit your next manuscript at $>$ springeropen.com 